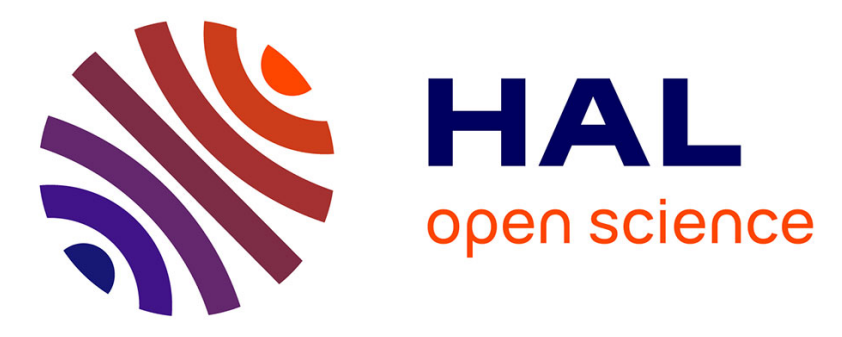

\title{
Spectroscopic Evidence for Superexchange in the Ferrimagnetic Spinel FeCr2S4
}

Sorin G Chiuzbăian, Stefania Brignolo, Coryn F Hague, Renaud Delaunay,

Marco Guarise, Alessandro Nicolaou, Zhaorong Yang, Haidong Zhou, Jean-Michel Mariot

\section{To cite this version:}

Sorin G Chiuzbăian, Stefania Brignolo, Coryn F Hague, Renaud Delaunay, Marco Guarise, et al.. Spectroscopic Evidence for Superexchange in the Ferrimagnetic Spinel FeCr2S4. Journal of Physical Chemistry C, 2017, 121 (40), pp.22369-22376. 10.1021/acs.jpcc.7b07471 . hal-02881461

\section{HAL Id: hal-02881461 https: / hal.sorbonne-universite.fr/hal-02881461}

Submitted on 25 Jun 2020

HAL is a multi-disciplinary open access archive for the deposit and dissemination of scientific research documents, whether they are published or not. The documents may come from teaching and research institutions in France or abroad, or from public or private research centers.
L'archive ouverte pluridisciplinaire HAL, est destinée au dépôt et à la diffusion de documents scientifiques de niveau recherche, publiés ou non, émanant des établissements d'enseignement et de recherche français ou étrangers, des laboratoires publics ou privés. 


\title{
Spectroscopic Evidence for Superexchange in the Ferrimagnetic Spinel $\mathrm{FeCr}_{2} \mathrm{~S}_{4}$
}

\author{
Sorin G. Chiuzbăian, ${ }^{*, \dagger, \ddagger}$ Stefania Brignolo, ${ }^{\dagger, \ddagger}$ Coryn F. Hague, ${ }^{\dagger, \ddagger}$ \\ Renaud Delaunay, ${ }^{\dagger} \ddagger$ Marco Guarise, ${ }^{\dagger, \perp}$ Alessandro Nicolaou, ${ }^{\ddagger}$ Zhaorong Yang, , \\ Haidong Zhou, ${ }^{\S, \|}$ and Jean-Michel Mariot ${ }^{\dagger, \ddagger}$ \\ †Sorbonne Universités, UPMC Univ Paris 06, CNRS, Laboratoire de Chimie \\ Physique-Matière et Rayonnement (UMR 7614), 4 place Jussieu, 75252 Paris Cedex 05, \\ France \\ ‡Synchrotron SOLEIL, L'Orme des Merisiers, Saint-Aubin, B.P. 48, 91192 Gif-sur-Yvette, \\ France \\ \High Magnetic Field Laboratory, Chinese Academy of Sciences, Hefei 230031, China \\ $\S$ University of Tennessee, Department of Physics and Astronomy, Experimental Condensed \\ Matter Physics, 407A Nielsen Physics Building, Knoxville, TN 37996-1200, United States \\ ||National High Magnetic Field Laboratory, Florida State University, Tallahassee, \\ FL 32310, United States \\ $\perp$ Present address: Laboratório Nacional Luz Sincrotron, 10000 Campinas, Brazil
}

E-mail: gheorghe.chiuzbaian@upmc.fr 


\begin{abstract}
Low-energy orbital excitations in spinel $\mathrm{FeCr}_{2} \mathrm{~S}_{4}$ have been studied element specifically at both Fe and Cr 2p-3d resonances by resonant inelastic X-ray scattering (RIXS). As a first step X-ray absorption spectroscopy measurements confirmed that iron, located at the tetrahedral $\left(T_{d}\right)$ sites of the spinel structure, was in a $\mathrm{Fe}^{2+}\left(\mathrm{d}^{6}\right)$ state and chromium, located at the octahedral $\left(O_{h}\right)$ sites, was in a $\mathrm{Cr}^{3+}\left(\mathrm{d}^{3}\right)$ state. We have identified RIXS spectral features with the help of crystal-field simulations that account consistently for on-site dd excitations and provide $10 D q=0.30 \pm 0.05 \mathrm{eV}$ for Fe $T_{d}$ sites and $10 D q=1.60 \pm 0.05 \mathrm{eV}$ for $\mathrm{Cr} O_{h}$ sites. The giant magneto-optical Kerr effect previously observed for photons with $0.3 \mathrm{eV}$ can be unambiguously attributed to the lowest possible dd excitations on the iron site $\mathrm{Fe}\left(t_{g}^{3} e^{3}\right) \rightarrow \mathrm{Fe}\left(t_{g}^{4} e^{2}\right)$. A $1.6 \mathrm{eV}$ energy-loss feature, measured in the Fe 2p-3d RIXS spectra, is found to be a two-site orbital excitation directly related to superexchange (SE) interaction between $\mathrm{Fe}$ and $\mathrm{Cr}$ cations. It opens new perspectives for applying RIXS to study SE in a broad range of 3d transition metal compounds.
\end{abstract}

\title{
Introduction
}

The longstanding focus on the cooperative magnetic exchange interactions in inorganic compounds ${ }^{1}$ is currently shifting towards the expanding field of magnetic metal-organic frameworks (MOFs) ${ }^{2}$ and single-molecule magnets (SMMs). ${ }^{3,4}$ Magnetic MOFs and SMMs generally involve elements of the first transition metal series. Data storage and multiferroics are the driving force behind the search for such novel materials (see, e.g., References 5 and 6). In this contribution we demonstrate the use of resonant inelastic X-ray scattering (RIXS) measurements to confirm the presence of superexchange (SE) interactions between two metal centers carrying magnetic moments. This can be seen as a precursor to the study of engineered magnetic MOFs, where ligands play a role via long- and short-range SE interaction. ${ }^{7}$

Progress in synchrotron radiation techniques has notably made RIXS accessible for prob- 
ing the chemical properties of complex materials. ${ }^{8-10}$ The inelastic scattering process involves the resonant excitation and decay of a core hole. It is often referred to as resonant X-ray Raman spectroscopy. Neutral excitations are created as in standard Raman and UV-vis spectroscopies but the advantage is that it provides access to electronic, magnetic, and vibrational excitations that bypass selection rules applying to classical optical excitations. It is a major addition also because of its intrinsic chemical selectivity.

Goodenough, Kanamori, and Anderson (GKA) ${ }^{1,11,12}$ demonstrated that optical and magnetic properties are interrelated through the SE mechanism. Since, theoretical models have been developed to describe the energetics of electronic excitations (on-site orbital excitations, inter-site charge transfers). Within a chemical-bond approach, ${ }^{13,14}$ a fragment of an extended system is treated as an entity where the quantities of interest are obtained through the diagonalization of molecule-like Hamiltonians. RIXS can be used to map such neutral excitations. Consider the $\mathrm{Ni}-\mathrm{O}$ bonds in nickel oxide. RIXS measurements at the Ni $\mathrm{K}$ $(1 \mathrm{~s}-3 \mathrm{~d}),{ }^{15} \mathrm{Ni} \mathrm{L} \mathrm{L}_{2,3}(2 \mathrm{p}-3 \mathrm{~d}),{ }^{16}$ and $\mathrm{Ni} \mathrm{M}_{2,3}(3 \mathrm{p}-3 \mathrm{~d}){ }^{17,18}$ edges map the dd excitations on $\mathrm{Ni}$ sites, as well as the ligand to metal charge-transfer (CT) excitations. Because of orbital hybridization, electrons can be exchanged between $\mathrm{Ni}$ and $\mathrm{O}$ sites. This makes it possible to obtain the fingerprint of $\mathrm{Ni}$ dd excitations following a resonant core-hole creation on $\mathrm{O}$ sites. ${ }^{19}$ In fact, because of the SE, dd excitations occurring at a metal site can propagate in extended systems, under certain conditions, as two-site orbital excitations or "orbitons". ${ }^{20-23}$ The latter are quasiparticles bearing momentum dependence. However, since the SE is essentially treated within a chemical-bond approach, spectroscopic evidence for SE should be available without the need for specific information concerning momentum dependence and therefore applicable to molecular systems lacking of translational symmetry. This represents the main goal of the present paper.

Spinel ferrites with the $\mathrm{AB}_{2} \mathrm{X}_{4}$ structure, under study since the discovery of their ferrimagnetism by Néel, ${ }^{24}$ are convenient candidates for exploring SE interaction between heterogeneous metal centers. They are subject to both cation and anion chemical substitution 
with a potential for finely modifying their electronic structure. For thiospinels $(X=S)$, there are two kinds of crystallographic sites: tetrahedral A sites and octahedral B sites. Studies in the 50's and 60's showed that $\mathrm{FeCr}_{2} \mathrm{~S}_{4}$ is a ferrimagnetic semiconductor that exhibits a magnetoresistive effect around the Néel temperature $\left(T_{\mathrm{N}} \approx 180 \mathrm{~K}\right) .{ }^{25,26}$ The electronic structure of $\mathrm{FeCr}_{2} \mathrm{~S}_{4}$ was discussed phenomenologically by Goodenough in relation to the degree of covalent mixing between d electrons and the s, p orbitals of the sulfur ions. ${ }^{27}$

Interest was revived in 1997, when Ramirez et al. measured a magnetoresistive ratio of $\approx 20 \%$ in $\mathrm{FeCr}_{2} \mathrm{~S}_{4},{ }^{28}$ that is to say somewhat comparable to that of $\mathrm{R}_{1-x} \mathrm{M}_{x} \mathrm{MnO}_{3}(\mathrm{R}=$ rare earth; $\mathrm{M}=\mathrm{Ca}, \mathrm{Sr}, \mathrm{Ba}$, and $\mathrm{Pb})$ manganites $(\approx 50-80 \%) .{ }^{29}$ More recently $\mathrm{FeCr}_{2} \mathrm{~S}_{4}$ has been earmarked as possibly having a multiferroic ground state which, because of its net magnetic moment, would open up new perspectives for potential applications. ${ }^{30,31}$ Optical reflectivity measurements by Ohgushi et al. revealed a giant magneto-optical Kerr effect (MOKE) in the $\mathrm{AB}_{2} \mathrm{X}_{4}$ spinel compounds. ${ }^{32,33}$ For $\mathrm{FeCr}_{2} \mathrm{~S}_{4}$, a Kerr rotation of $\approx 4.3^{\circ}$ was measured at low temperature, which has led to further investigations of the low temperature properties, with and without cation and anion substitution (see, e.g., References 34 and 35).

The RIXS measurements at Fe and $\mathrm{Cr} 2 \mathrm{p}-3 \mathrm{~d}$ thresholds in $\mathrm{FeCr}_{2} \mathrm{~S}_{4}$ presented here map the local and non-local neutral electronic excitations in considerable detail thus shedding light on the SE interaction. Such measurements, even when performed in the soft X-ray energy region, are bulk sensitive because the photon attenuation lengths are of the order of few hundred nanometers. ${ }^{36}$

For the interpretation of the orbital excitations, we have computed the relevant TanabeSugano (TS) diagrams ${ }^{37}$ as a means of distinguishing between purely crystal-field (CF) effects and ligand field interactions.

Following a description of the experimental conditions and the investigated material, the RIXS data at Fe and $\mathrm{Cr} 2 \mathrm{p}-3 \mathrm{~d}$ thresholds are presented and discussed in relation with multiplet calculations. The data are then examined together for signs of SE interaction and as a complementary aid to the understanding of the giant MOKE effect. Conclusions are 
drawn in the last section.

\section{Methods and material}

\section{Experimental conditions for RIXS measurements.}

The measurements were performed using the AERHA end station ${ }^{38}$ installed on the SEXTANTS beam line ${ }^{39}$ at the SOLEIL synchrotron radiation facility. Fe and Cr 2p Xray absorption spectra (XAS) were recorded in the total electron-yield mode in order to select suitable excitation energies for the RIXS measurements. For the XAS measurements the beam impinged on the sample at normal incidence. The beamline apertures were selected to provide an energy resolution of $120 \mathrm{meV}$ at the Fe $2 \mathrm{p}$ edge and of $110 \mathrm{meV}$ at the $\mathrm{Cr} 2 \mathrm{p}$ edge.

The incoming beam was incident at a grazing angle of $20^{\circ}$ with respect to the sample surface for the RIXS experiments. It was focused down to approximately $2 \mu \mathrm{m}$ fwhm vertically on the sample surface. The vertical plane is the dispersive plane for the spectrometer. The beam was approximately $150 \mu \mathrm{m}$ wide in the non-dispersive horizontal plane. The setup procedure includes aligning the beam focus and the spectrometer's $2.5 \mu \mathrm{m} \times 2 \mathrm{~mm}$ entrance slit which marks the first focus of the elliptical collecting mirror. Linear polarization was used with the electric vector in the scattering plane. The scattered X-rays were observed at $95^{\circ}$ to the incident beam. The spectra were recorded using the 1800 lines $/ \mathrm{mm}$ diffraction grating of the AERHA spectrometer and a $2048 \times 2048$ pixel CCD detector (physical pixel size $13.5 \mu \mathrm{m}$ ) cooled to $-110^{\circ} \mathrm{C}$. One of the features of the spectrometer is that its resolution can be adjusted to enhance transmission as required. Details can be found in Reference 38. Good counting statistics were obtained with an overall energy resolution of $250 \mathrm{meV}$ fwhm at the $\mathrm{Fe} 2 \mathrm{p}_{3 / 2}$ edge and $230 \mathrm{meV}$ fwhm at the $\mathrm{Cr} 2 \mathrm{p}_{3 / 2}$ edge, as estimated from Gaussian fits to the off-resonance elastic peaks.

XAS measurements were performed at room temperature (RT) under a pressure lower 
than $5 \times 10^{-9}$ mbar. RIXS spectra were recorded at RT and at $30 \mathrm{~K}$.

$\mathrm{FeCr}_{2} \mathrm{~S}_{4}$ single crystals were grown by the chemical vapor transport method in evacuated sealed quartz tubes. ${ }^{40} \mathrm{CrCl}_{3}$ was used as a transport agent. During the growth process, the temperature at one end of the quartz tube was kept at $900{ }^{\circ} \mathrm{C}$ and $850{ }^{\circ} \mathrm{C}$ at the other. Crystals were bound to the sample holder with a conductive epoxy resin. To minimize surface contamination, the sample was cleaved in a load lock under $3 \times 10^{-8}$ mbar and immediately transferred to the analysis chamber.

\section{Modeling.}

All spectral simulations and calculations of TS diagrams were performed using the CTM4XAS atomic multiplet program ${ }^{41}$ based on Cowan's code. ${ }^{42}$ The expansion of the electronic cloud around the $\mathrm{Fe}^{2+}$ and $\mathrm{Cr}^{3+}$ ions in the compound compared to the free ions was accounted for by a reduction factor $\beta=0.80 \pm 0.05$ (nephelauxetic ratio) of the SlaterCondon integrals calculated within the Hartree-Fock scheme in spherical symmetry. The XAS transition rates are calculated as:

$$
I^{\mathrm{XAS}} \propto\left|\left\langle i\left|T^{(\mathrm{a})}\right| g\right\rangle\right|^{2}
$$

where $T^{(\mathrm{a})}$ represents the electric dipole operator for the transition from the ground state $|g\rangle=\left|2 \mathrm{p}^{6} 3 \mathrm{~d}^{n}\right\rangle$ to the $|i\rangle=\left|2 \mathrm{p}^{5} 3 \mathrm{~d}^{n+1}\right\rangle$ core-hole states considered within the corresponding symmetries. The RIXS spectra are calculated on the basis of the Kramers-Heisenberg equation: ${ }^{43}$

$$
\begin{aligned}
& I^{\mathrm{RIXS}} \propto \sum_{f}\left|\sum_{i} \frac{\left\langle f\left|T^{(\mathrm{e})}\right| i\right\rangle\left\langle i\left|T^{(\mathrm{a})}\right| g\right\rangle}{E_{g}+\hbar \omega_{\text {in }}-E_{i}-i \Gamma_{i} / 2}\right|^{2} \\
& \times \frac{1}{\pi} \frac{\Gamma_{f} / 2}{\left(E_{i}-E_{f}+\hbar \omega_{\text {in }}-\hbar \omega_{\text {out }}\right)^{2}+\left(\Gamma_{f} / 2\right)^{2}}
\end{aligned}
$$


where $|f\rangle=\left|2 \mathrm{p}^{6} 3 \mathrm{~d}^{n}\right\rangle$ are CF multiplets reached after scattering through the dipole emission operator $T^{(\mathrm{e})}, \hbar \omega_{\text {in }}\left(\hbar \omega_{\text {out }}\right)$ are the energies of the incoming (scattered) photons, $\Gamma_{i}$ is the lifetime (Lorentzian) broadening of the $2 \mathrm{p}$ core-hole state, and $\Gamma_{f}$ is the lifetime broadening of orbitally excited states. For $\mathrm{Fe}^{2+}, \Gamma_{i}$ was set to $0.20 \mathrm{eV}(0.37 \mathrm{eV})$ at the $2 \mathrm{p}_{3 / 2}\left(2 \mathrm{p}_{1 / 2}\right)$ resonances; for $\mathrm{Cr}^{3+}$, the $\Gamma_{i}$ values were $0.20 \mathrm{eV}$ and $0.29 \mathrm{eV}$ for $2 \mathrm{p}_{3 / 2}$ and $2 \mathrm{p}_{1 / 2}$ resonances, respectively. ${ }^{44,45} \Gamma_{f}$ was formally set to $0.001 \mathrm{eV}$ in all cases, as core-hole free states have significantly larger lifetime. The magnitude of the CF splitting $10 D q$ was treated as a parameter to find the best agreement between simulated data and measured spectra. In order to reduce the number of parameters, CT excitations were not considered in the XAS/RIXS modeling. Their inclusion might improve the agreement between the simulated and measured XAS intensity after the white line. Accounting for CT excitations in RIXS simulations would have no impact on the position of the CF multiplets. Final states with an electron transfer from the ligand (sulfur) to the metal would shift some spectral weight from the dd excitations to above $\left(\hbar \omega_{\text {in }}-\hbar \omega_{\text {out }}\right) \approx 2 \mathrm{eV}$, where $\mathrm{CT}$ excitations are typically expected. All calculated spectra were convoluted with a Gaussian profile to include the experimental broadening. Details are given along in the following.

\section{Results and analysis}

In the following, the experimental results are presented and discussed in relation to multiplet calculations: first for the Fe sites, then for the Cr sites. This is followed by a general comparison between Fe and Cr RIXS data and an analysis of the implications for the exchange interactions across the sulfur ligands. Finally our findings are confronted to previously reported optical reflectivity data ${ }^{32,33}$ and recent magnetic measurements. ${ }^{30}$ 


\section{Fe site.}

Figure 1 shows the Fe 2p XAS measurement on $\mathrm{FeCr}_{2} \mathrm{~S}_{4}$ and the corresponding simulated spectra. Our XAS data are in agreement with previously reported measurements. ${ }^{46,47}$ XAS measurements on $\mathrm{FeCr}_{2} \mathrm{O}_{4}{ }^{46}$ and $\mathrm{FeCr}_{2} \mathrm{Se}_{4}{ }^{48}$ display comparable Fe 2p XAS spectra, with a general shape very similar to that of divalent $\mathrm{Fe}$ in FeO. ${ }^{46}$ Trivalent $\mathrm{Fe}$, as in $\mathrm{Fe}_{2} \mathrm{O}_{3}$, has a recognizably different spectrum: it exhibits a pronounced multiplet structure with the $2 \mathrm{p}_{3 / 2}$ white line that is shifted by $\approx 2 \mathrm{eV}$ towards higher photon energies. ${ }^{49}$ The divalent character of iron in $\mathrm{FeCr}_{2} \mathrm{~S}_{4}$ is also consistent with the multiplet splitting observed in the Fe 3s X-ray photoelectron spectrum of this compound. ${ }^{50}$

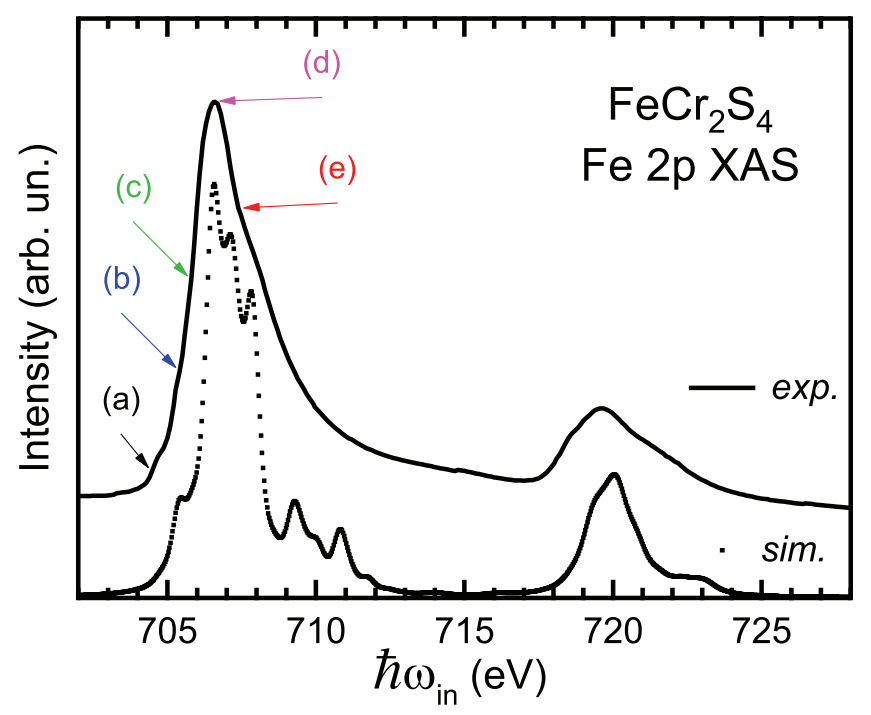

Figure 1: Fe 2p XAS for $\mathrm{FeCr}_{2} \mathrm{~S}_{4}$ : measured (continuous line) and simulated (dots). Arrows on the experimental spectrum indicate the incoming photon energies used for the RIXS measurements: (a) $704.4 \mathrm{eV}$, (b) $705.4 \mathrm{eV}$, (c) $705.8 \mathrm{eV}$, (d) $706.6 \mathrm{eV}$, and (e) $707.3 \mathrm{eV}$. The simulation is obtained from a CF multiplet calculation for $\mathrm{Fe}^{2+}$ within the $T_{d}$ symmetry with $10 D q=0.3 \mathrm{eV}$. Though the main atomic features can be identified with structure in the experimental spectrum, sharp calculated features are attenuated due to the covalent nature of the compound and the absence of $\mathrm{CT}$ in the calculation.

It should also be noted that $\mathrm{Fe}$ has $T_{d}$ symmetry in $\mathrm{FeCr}_{2} \mathrm{~S}_{4}$ and $\mathrm{FeCr}_{2} \mathrm{O}_{4}$, but has $\mathrm{O}_{h}$ symmetry in $\mathrm{FeCr}_{2} \mathrm{Se}_{4} \cdot \mathrm{FeCr}_{2} \mathrm{~S}_{4}$ has the spinel structure, whilst that of $\mathrm{FeCr}_{2} \mathrm{Se}_{4}$ is monoclinic. The fact that the $\mathrm{FeCr}_{2} \mathrm{~S}_{4}$ and $\mathrm{FeCr}_{2} \mathrm{Se}_{4} \mathrm{XAS}$ spectra are broader than that of $\mathrm{FeCr}_{2} \mathrm{O}_{4}$ is related to the lower ionicity of the $\mathrm{Fe}-\mathrm{S}$ and $\mathrm{Fe}-\mathrm{Se}$ bonds compared to that 
of the $\mathrm{Fe}-\mathrm{O}$ bond ( $\mathrm{S}$ and Se have a comparable electronegativity, significantly smaller than that of $\mathrm{O}$ ). The absence of significant differences in the multiplet structure of the $\mathrm{FeCr}_{2} \mathrm{X}_{4}$ XAS spectra points to a high degree of Fe 3d itinerancy in these compounds.

The simulated spectrum in Figure 1 was obtained from a CF multiplet calculation for $\mathrm{Fe}^{2+}$ within the $T_{d}$ symmetry with $10 D q=0.3 \mathrm{eV}$, a value deduced from the RIXS simulations (see below). Both the Lorentzian and Gaussian broadenings mentioned above were included. $\mathrm{CT}$ is not taken into account. The agreement with experiment is good in so far as the shape of the simulated spectrum displays the same features albeit with finer multiplet structure.

The Fe $2 \mathrm{p}_{3 / 2}-3 \mathrm{~d}$ RIXS data (Figure 2) show no differences between RT and $30 \mathrm{~K}$ measurements other than a small change in the amplitude of the elastic peak. The latter can be due to a small shift of the sample position upon cooling, which results in a variation of the diffuse reflectivity because of a change of the surface morphology.

The $T_{d}$ crystal field acting on the $\mathrm{Fe}^{2+}$ site partially lifts the degeneracy of atomic $3 \mathrm{~d}^{6}$ terms, as illustrated at the bottom of Figure 2, taking the spin-orbit parameter of the $3 \mathrm{~d}$ electrons $\zeta(3 \mathrm{~d})$ as zero. In fact $\zeta(3 \mathrm{~d})$ is $53 \mathrm{meV}$ for the $\mathrm{Fe}^{2+}$ free ion (see Reference 51), a value that is too small to be resolved under the present experimental conditions. The first $\mathrm{CF}$ excitation measured at $0.33 \mathrm{eV}$ energy loss unambiguously determines the $\mathrm{CF}$ strength on the $\mathrm{Fe}^{2+}$ site. We take it as $10 D q=0.30 \pm 0.05 \mathrm{eV}$. The full TS diagram computed for $\mathrm{Fe}^{2+}$ in $T_{d}$ with the Racah parameter $B=0.117 \mathrm{eV}$ and $\zeta(3 \mathrm{~d})=0 \mathrm{eV}$ is given in the supporting information, Figure S1. The first energy loss corresponds to the $e^{3} t_{2}^{3}\left[{ }^{5} E\left({ }^{5} D\right)\right] \rightarrow e^{2} t_{2}^{4}\left[{ }^{5} T_{2}\left({ }^{5} D\right)\right]$ transition and matches a resonance in the optical conductivity data. ${ }^{32,33}$ Further dd excitations can be attributed to transitions from the ground state to ${ }^{3} T_{1}$ and ${ }^{3} E$ excited states at transferred energies higher than $2.1 \mathrm{eV}$. The RIXS spectral weights include convolution with a $250 \mathrm{meV}$ fwhm Gaussian profile to account for the combined experimental resolution (see Section "Methods and material"). The calculated spectra correctly reproduce the energy loss at $0.3 \mathrm{eV}$ and $\mathrm{dd}$ excitations from $\approx 2 \mathrm{eV}$ to $4 \mathrm{eV}$ on the transferred energy scale. But we underline that, contrary to observation, no peak is predicted at an energy loss of $1.6 \mathrm{eV}$. 


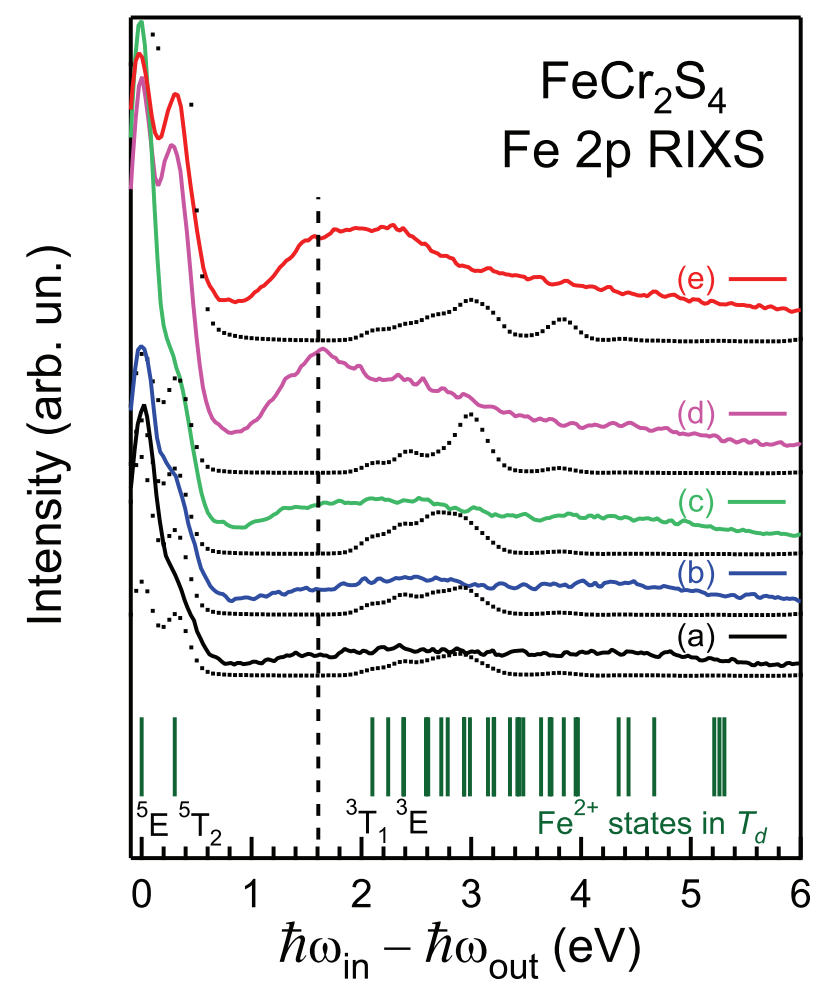

Figure 2: $\mathrm{FeCr}_{2} \mathrm{~S}_{4}$ RIXS recorded across the Fe $2 \mathrm{p}_{3 / 2}$ edge (the intensities are normalized to the acquisition time). The lines are the experimental data (the letters refer to incoming photon energies $\hbar \omega_{\text {in }}$ as indicated in Figure 1). The simulated spectra result from CF multiplet calculations for a $\mathrm{Fe}^{2+}$ ion in $T_{d}$ symmetry with $10 D q=0.3 \mathrm{eV}$. The RIXS final states are shown as vertical bars. The feature at $1.6 \mathrm{eV}$ is not accounted for by the CF-based calculations.

Other than the first loss peak the calculated RIXS spectrum starts at $2 \mathrm{eV}$ and the main feature reaches maximum intensity on resonance at $\approx 3 \mathrm{eV}$ transferred energy. The origin of the extra peak observed experimentally is to be found elsewhere as discussed later.

\section{Cr site.}

In Figure 3, we compare measured and simulated Cr 2p XAS spectra for $\mathrm{FeCr}_{2} \mathrm{~S}_{4}$. The XAS measurement supports the assumption that chromium is in $3+$ state. $^{50}$ This is also supported by the $\mathrm{Cr}$ 3s multiplet splitting observed by X-ray photoelectron spectroscopy in a series of trivalent chromium compounds. ${ }^{50}$

The simulated spectrum is obtained from a CF multiplet calculation for a $\mathrm{Cr}^{3+}$ ion 


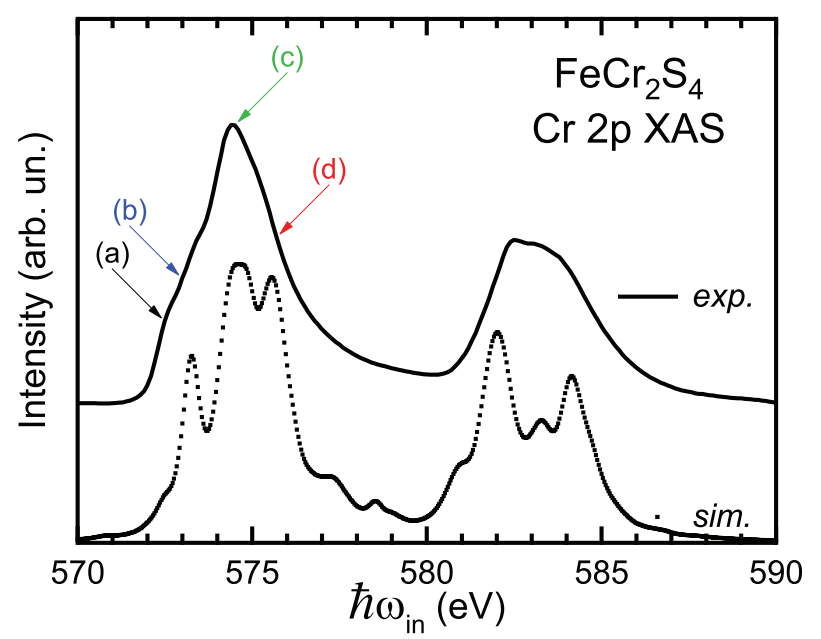

Figure 3: Cr 2p XAS for $\mathrm{FeCr}_{2} \mathrm{~S}_{4}$ : measured (line) and simulated (dots). Arrows on the experimental spectrum indicate the incoming photon energies used for the RIXS measurements: (a) $572.5 \mathrm{eV}$, (b) $573.0 \mathrm{eV}$, (c) $574.5 \mathrm{eV}$, and (d) $575.7 \mathrm{eV}$. The simulation is obtained for $\mathrm{Cr}^{3+}$ within the $O_{h}$ symmetry with $10 D q=1.6 \mathrm{eV}$.

in the $O_{h}$ symmetry with $10 D q=1.6 \mathrm{eV}$. This $10 D q$ value is consistent with the RIXS data (see below); it is also consistent with band structure calculations. ${ }^{52,53} \mathrm{CT}$ is not taken into account. Both lifetime and instrumental broadenings are taken into account in the simulation (see Section "Methods and material"). The calculated spectrum is broadened with a Lorentzian profile with a fwhm of $0.2 \mathrm{eV}$ across the $2 \mathrm{p}_{3 / 2}$ resonance and with a fwhm of $0.29 \mathrm{eV}$ across the $2 \mathrm{p}_{1 / 2}$ resonance to allow for lifetime broadening ${ }^{45}$ and with a Gaussian profile with a fwhm of $0.11 \mathrm{eV}$ to account for instrumental broadening. The calculation adequately explains the general shape of the experimental data, though it is closer to the XAS spectrum of $\mathrm{Cr}_{2} \mathrm{O}_{3},{ }^{54}$ a more ionic compound, in which $\mathrm{Cr}^{3+}$ ions are also in an $O_{h}$ environment. This falls within our expectations, since multiplet calculations are performed for pure ionic states.

The $\mathrm{Cr} 2 \mathrm{p}_{3 / 2}-3 \mathrm{~d}$ RIXS measurements at RT are shown on a transferred energy scale in Figure 4. Comparing the calculated excited states for a $\mathrm{Cr}^{3+}$ ion in $O_{h}$ symmetry with experiment [see also the full TS diagram given in the supporting information, Figure S2, for the Racah parameter $B=0.115 \mathrm{eV}$ and $\zeta(3 \mathrm{~d})=0 \mathrm{eV}]$ shows us that the loss peak at $1.6 \mathrm{eV}$ can be attributed to the first dd excitation corresponding to the transition between 


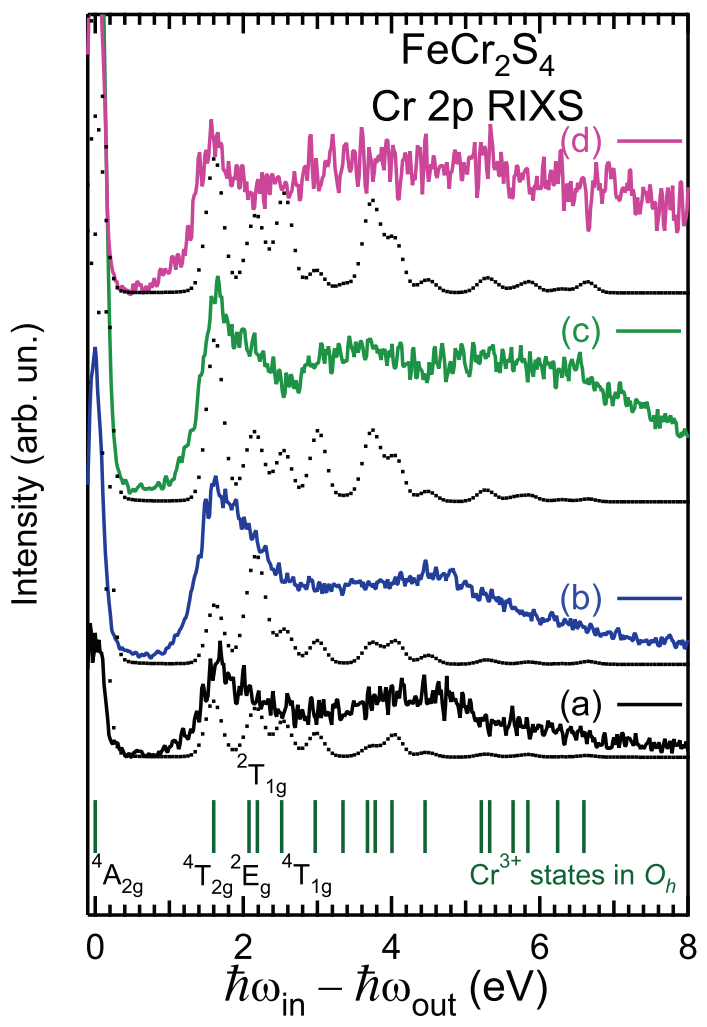

Figure 4: $\mathrm{FeCr}_{2} \mathrm{~S}_{4}$ RIXS recorded across the $\mathrm{Cr} 2 \mathrm{p}_{3 / 2}$ edge (the intensities are normalized to the acquisition time). The lines are the experimental data (the letters refer to incoming photon energies $\hbar \omega_{\text {in }}$ as indicated in Figure 3$)$. The simulated spectra result from CF multiplet calculations for a $\mathrm{Cr}^{3+}$ ion in $O_{h}$ symmetry with $10 D q=1.6 \mathrm{eV}$. The RIXS final states are shown as vertical bars.

the ground state $t_{2 g}^{3}\left({ }^{4} A_{2 g}\right)$ and the first excited state $\left.t_{2 g}^{2} e_{g}^{1}\left({ }^{4} T_{2 g}\right)\right)$. The high energy-loss side of this peak is made up of contributions from dd excitations involving states lying at higher energy (i.e., ${ }^{2} E_{1 g},{ }^{2} T_{1 g}$ and ${ }^{4} T_{1 g}$ states) and from CT states as well. The agreement between the calculated and experimental spectra could be improved by including CT by means of additional adjustable parameters. This would not modify the position of the dd excitations but add CT spectral weight mainly at higher transfer energies. For the purpose of understanding the origin of the $1.6 \mathrm{eV}$ peak this would be superfluous as discussed below.

Although $\mathrm{FeCr}_{2} \mathrm{~S}_{4}$ is paramagnetic at room temperature, short range magnetic order persists. Our measurements at $30 \mathrm{~K}$ are well below the ferrimagnetic ordering temperature but only minor differences were observed either side of $T_{\mathrm{N}} \approx 180 \mathrm{~K}$ as already pointed out for the Fe RIXS data. 


\section{Discussion}

Our observation from XAS and RIXS favors $\mathrm{Cr}^{3+}$ and $\mathrm{Fe}^{2+}$ oxidation states. It should be born in mind, however, that these are atom specific probes that involve a core-hole potential $U_{\mathrm{dc}}$, typically $1 \mathrm{eV}$ larger than the Coulomb repulsion energy $U_{\mathrm{dd}} \cdot{ }^{55}$ Recently Lo Presti and Destro ${ }^{56}$ have examined the formal oxidation state of $\mathrm{Fe}$ and $\mathrm{Cr}$ in $\mathrm{FeCr}_{2} \mathrm{~S}_{4}$ using high resolution X-ray diffraction and unrestricted Hartree-Fock calculations applied to the experimentally determined structure. They conclude that Fe is close to $2+$, but $\mathrm{Cr}$ has a slightly lower d density than would be expected for $3+$.

Contrary to spectra in the optical regime, RIXS can map excitations that involve changes of multiplicity via two electric dipole transitions. dd excitations on Fe and $\mathrm{Cr}$ sites show up at constant energy loss [i.e., $\left(\hbar \omega_{\text {in }}-\hbar \omega_{\text {out }}\right)$ is constant] in Figures 2 and 4 , thus similar to Raman spectra. For excitations above threshold, normal X-ray fluorescence sets in. The energy of $\hbar \omega_{\text {out }}$ is then independent of $\hbar \omega_{\text {in }}$ and the X-ray emission band represents, to a first approximation, the partial electronic densities of valence states; in our case $\mathrm{Cr}$ or Fe $3 \mathrm{~d}$ states hybridized with the sulfur 3sp band. The Raman regime can however also extend beyond the absorption threshold in the shape of localized excitonic states. ${ }^{57}$ In Figure 5 we present spectra for a few excitation energies on an emitted photon energy scale after subtraction of the $\mathrm{Cr}$ and Fe absorption threshold energies $\left(\hbar \omega_{\text {out }}-E_{\text {edge }}\right)$, where $E_{\text {edge }}$ is $575.0 \mathrm{eV}$ for $\mathrm{Cr}$ and $707.1 \mathrm{eV}$ for Fe. On this scale, zero energy marks the limit between the X-ray Raman regime and the X-ray fluorescence regime: the elastic peak has negative energy values for the Raman regime; fluorescence sets in for positive excitation energies.

Figure 5 spotlights the salient features that we wish to discuss. The $\mathrm{Cr} 1.6 \mathrm{eV}$ loss peak is observed even for excitations above threshold and remains intense relative to the elastic

peak. It is straightforwardly attributable to a $\left(t_{2 g}^{3} \rightarrow t_{2 g}^{2} e_{g}^{1}\right)$ dd excitation. On the other hand the first Fe dd excitation at $0.33 \mathrm{eV}$ weakens above zero.

Despite the partially covalent character of the compound we observe that the $\mathrm{Fe}$ and $\mathrm{Cr}$ elementary excitations are well accounted for by the TS diagrams for $\mathrm{Fe}^{2+}$ in $T_{d}$ symmetry 


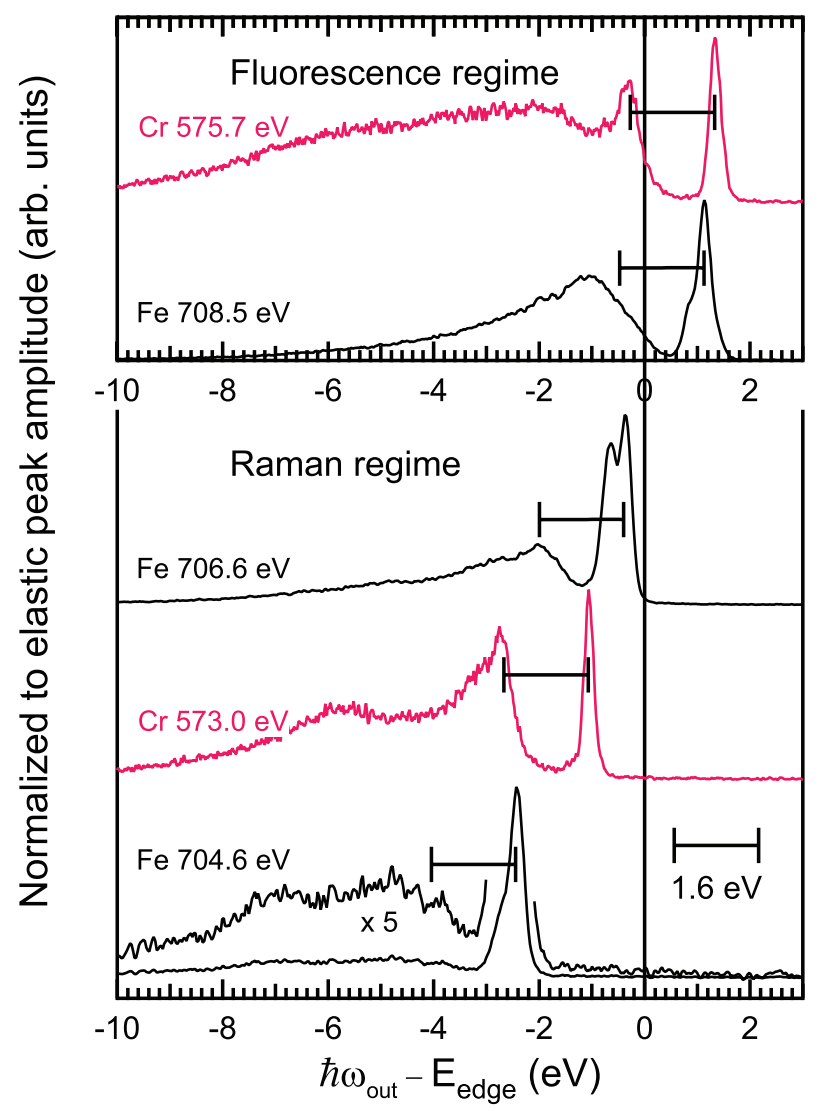

Figure 5: Fe and $\mathrm{Cr} 2 \mathrm{p}_{3 / 2}$ RIXS of $\mathrm{FeCr}_{2} \mathrm{~S}_{4}$ shown on an emitted photon energy scale from which the respective $2 \mathrm{p}_{3 / 2}$ threshold energies have been subtracted. Thus the fluorescence regime is reached for elastic peaks above zero energy. Elastic peaks below zero energy indicate spectra in the Raman regime. As a guide, a $1.6 \mathrm{eV}$ dimension line is shown in each case. The $\mathrm{Cr}$ spectra shown here were taken at $30 \mathrm{~K}$.

and $\mathrm{Cr}^{3+}$ in $O_{h}$ symmetry except for the $1.6 \mathrm{eV}$ peak in the Fe RIXS spectrum. According to optical absorption, substitutional $\mathrm{Fe}^{2+}$ ions in cubic $\mathrm{ZnS}$ also shows a first dd excitation at $0.4 \mathrm{eV}$ followed by a gap before further loss structure appears above $2 \mathrm{eV}$; no significant structure is observed at $1.6 \mathrm{eV} .58$

The dependence of the $1.6 \mathrm{eV}$ peak as a function of $\hbar \omega_{\text {in }}$ strongly suggests that this is not due to CT. In particular it vanishes for $\hbar \omega_{\text {in }}$ greater than the threshold energy whereas the hybridization between the S 3p and Fe 3d states responsible for CT should also be evident in the fluorescence regime.

We situate $\mathrm{CT}$ at $\approx 4.5 \mathrm{eV}$ loss which is supported by $\mathrm{X}$-ray photoelectron spectroscopy (XPS) measurements of Fe 3p core levels in $\mathrm{FeCr}_{2} \mathrm{~S}_{4},{ }^{59}$ though the XPS value of $\approx 4 \mathrm{eV}$ 
would not necessarily be applicable to the RIXS data because of differences in Coulomb interaction and CT could extend to lower losses.

As an aid to discussing this further in relation with the orbital interactions we present the $\mathrm{FeCr}_{2} \mathrm{~S}_{4}$ unit cell in Figure 6. The $\mathrm{Cr}^{3+} \mathrm{S}_{6}^{2-}$ quasi-regular octahedrons share edges in the $\mathrm{FeCr}_{2} \mathrm{~S}_{4}$ structure. The half-filled $\mathrm{Cr} t_{2 g}$ orbitals are oriented almost orthogonally to the S 3p ligands. This leads to ferromagnetic alignment in accordance with GKA rules since electron transfer between $\mathrm{d}_{\mathrm{xy}}, \mathrm{d}_{\mathrm{xz}}, \mathrm{d}_{\mathrm{yz}}$ orbitals on two adjacent $\mathrm{Cr}$ sites cannot take place. The $\mathrm{Cr}-\mathrm{S}-\mathrm{Cr}$ bond angle is in fact $94^{\circ},{ }^{56}$ but the symmetry argument remains valid for angles not too far from $90^{\circ}$.

Fe atoms in tetrahedral symmetry lie at the center of a cube with only four corners occupied by $\mathrm{S}$ atoms to form the tetrahedron, the $t_{2}$ orbitals $\left(\mathrm{d}_{\mathrm{xy}}, \mathrm{d}_{\mathrm{xz}}\right.$ and $\left.\mathrm{d}_{\mathrm{yz}}\right)$ point to the mid-point of the cube edges and the $e$ orbitals $\left(\mathrm{d}_{z^{2}}\right.$ and $\left.\mathrm{d}_{\mathrm{x}^{2}-\mathrm{y}^{2}}\right)$ point to the cube faces. The $\mathrm{S}$ atoms are shared with the $\mathrm{Cr}$ octahedral structure and the $\mathrm{Fe}-\mathrm{S}-\mathrm{Cr}$ bond angle is $122^{\circ} .{ }^{56}$ The magnetic properties of $\mathrm{FeCr}_{2} \mathrm{~S}_{4}$ are in support of antiferromagnetic coupling between $\mathrm{Fe}$ and $\mathrm{Cr}$ sites but identification of the magnetic interactions in terms of exchange across $\mathrm{S} 3 \mathrm{p}$ orbitals is not as clear cut as when $180^{\circ}$ or $90^{\circ}$ GKA rules can be applied directly. What is clear is that the $\mathrm{Fe}^{2+}$ regular tetrahedrons are well separated from each other, so we can assume $\mathrm{Fe}-\mathrm{Fe}$ interactions are negligible compared to interactions between $\mathrm{Fe}^{2+}$ and $\mathrm{Cr}^{3+}$ across a single sulfur ion.

A rough estimate of the overlap between metal and ligand orbitals can be established by first imagining that the $\mathrm{Fe}-\mathrm{S}-\mathrm{Cr}$ bond angle is $90^{\circ}$. A S 3p ligand orbital drawn along the $c$-axis in Figure 6 will form a non-orthogonal weak $\mathrm{p}_{\pi}$-type bond with the $\mathrm{Cr} \mathrm{d}_{\mathrm{yz}}$ orbital. But, as viewed from the $\mathrm{Fe}^{2+}$ atom, one lobe of this $\mathrm{p}_{\pi}$-type bond is a $\mathrm{p}_{\sigma}$ orbital pointing towards the $\mathrm{Fe}$ atom. It mixes with $t_{2}$ orbitals but is not mixing with $e$ orbitals as the overlap is the same for positive and negative lobes both as concerns $\mathrm{d}_{\mathrm{x}^{2}-\mathrm{y}^{2}}$ and $\mathrm{d}_{\mathrm{z}^{2}}{ }^{60}$ This situation changes little as the $\mathrm{Fe}-\mathrm{S}-\mathrm{Cr}$ bond angle is increased by $32^{\circ}$ to reach the true $\mathrm{Fe}-\mathrm{S}-\mathrm{Cr}$ bond angle. For instance, the change in bond angle from $90^{\circ}$ to $122^{\circ}$ will cancel 

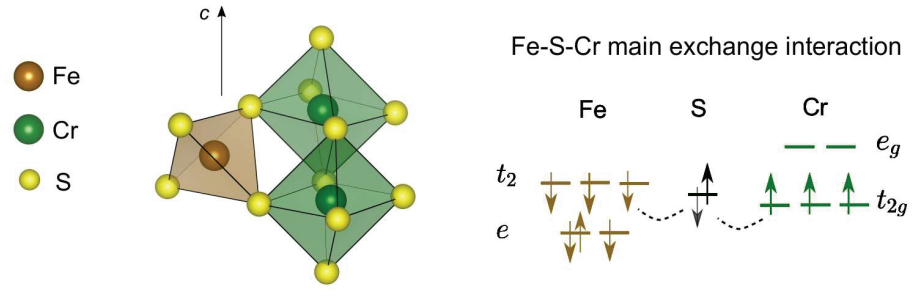

\section{$|g\rangle$}
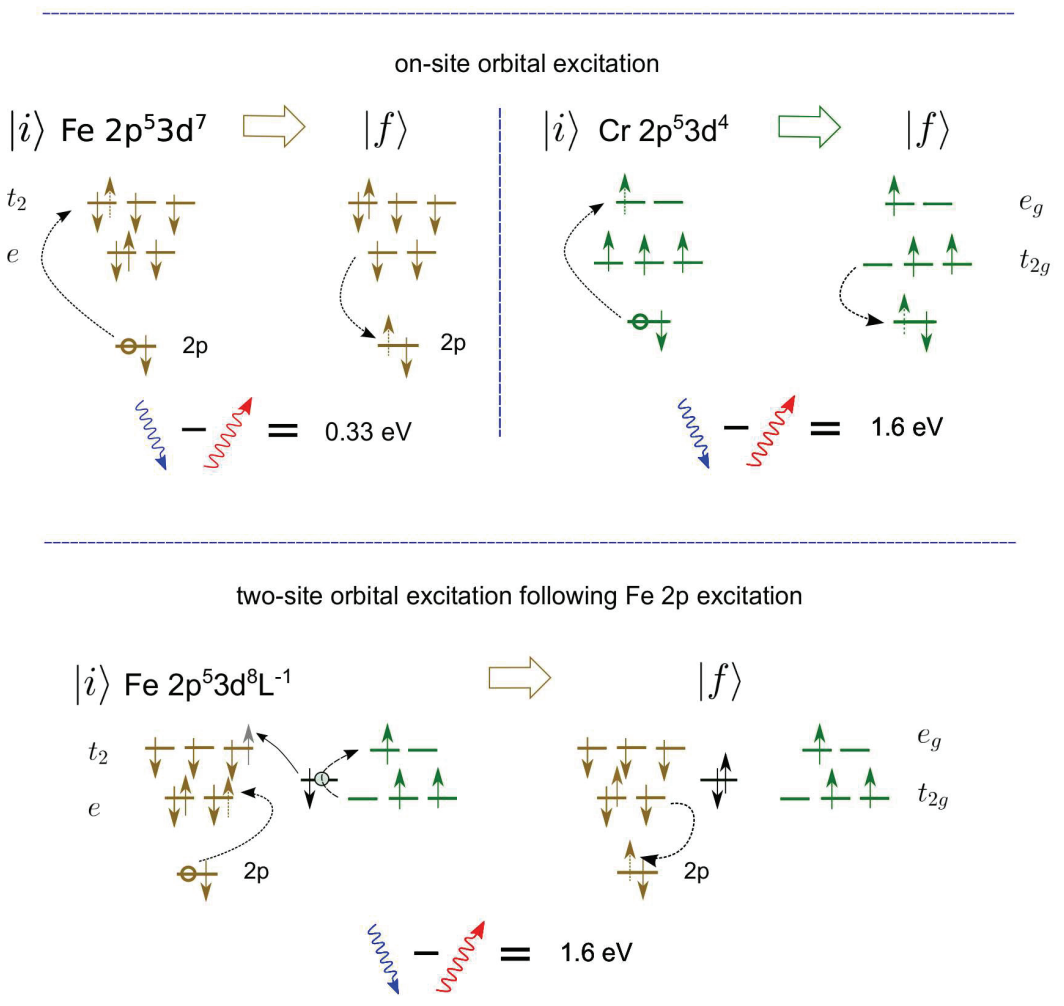

Figure 6: Portion of the $\mathrm{FeCr}_{2} \mathrm{~S}_{4}$ crystal structure (the crystallographic $c$-axis is indicated) along with a schematic representation of the antiferromagnetic coupling between $\mathrm{Fe}$ and $\mathrm{Cr}$ via the S 3p orbitals in the ground state $|g\rangle$ (top panel). On-site orbital excitations subsequent to the decay of the Fe $2 \mathrm{p}^{5} 3 \mathrm{~d}^{7}$ or $\mathrm{Cr} 2 \mathrm{p}^{5} 3 \mathrm{~d}^{4}$ intermediate states $|i\rangle$ are shown (middle panel). The Fe $2 \mathrm{p}^{5} 3 \mathrm{~d}^{8} \mathrm{~L}^{-1}$ intermediate state opens a spin-up channel for the $\operatorname{Cr}\left(t_{2 g}^{3} e_{g}^{0}\right)$ to $\operatorname{Cr}\left(t_{2 g}^{2} e_{g}^{1}\right)$ excitation (see bottom panel). The equivalent opening of the spin-down channel in the $\operatorname{Cr} 2 \mathrm{p}^{5} 3 \mathrm{~d}^{5} \mathrm{~L}^{-1}$ configuration cannot affect the Fe down-spin states that are full. It should be noted that there is no $\mathrm{CT}$ in the final states $|f\rangle$ represented here.

the strict orthogonality between $\mathrm{Fe} t_{2}$ and $\mathrm{S} p_{\sigma}$-like type orbitals; the resulting hybridization is however expected to be small. The covalent mixing $\lambda$ of non-orthogonal orbitals $i$ and $j$ can be estimated from the energy separation $\Delta \varepsilon_{i j}$ according to $\lambda \propto\left(\Delta \varepsilon_{i j}\right)^{-1}$. Applied to the half-filled $\mathrm{Fe} t_{2}$ and half-filled $\mathrm{Cr} t_{2 g}$ ground state, the main interaction should therefore be $\mathrm{Fe}\left(t_{2}^{3}\right)-\mathrm{S}-\mathrm{Cr}\left(t_{2 g}^{3}\right) \mathrm{SE}$. 
Support for this orbital-based picture and the ensuing antiferromagnetic interaction is provided by band structure calculations that also estimate the relative energies of the $\mathrm{d}$ states involved. That is to say that $\varepsilon\left[\mathrm{Fe}\left(t_{2}^{3}\right)\right] \approx \varepsilon\left[\mathrm{Cr}\left(t_{2 g}^{3}\right)\right] .{ }^{52,53}$ The $\mathrm{S} \mathrm{p}_{\pi}$ orbitals in the $T_{d}$ symmetry are difficult to visualize but it is clear that they will have sufficient $\mathrm{p}_{\sigma}$ character with respect to $\mathrm{Cr}$ to mix with its $\mathrm{d}_{\mathrm{x}^{2}-\mathrm{y}^{2}}, \mathrm{~d}_{\mathrm{z}^{2}}$ orbitals. It is easier to picture an effective $\mathrm{S} \mathrm{p}_{\sigma}$ orbital between $\mathrm{Fe}$ and $\mathrm{Cr}$ centers tilted by $29^{\circ}$ with respect to the respective true $\mathrm{p}_{\sigma}$ axes. The overlap with $\mathrm{Cr} e_{g}$ remains strong and on the Fe side it mainly overlaps the non-orthogonal $t_{2}$ orbitals.

The $2 \mathrm{p}-3 \mathrm{~d}$ absorption process at the Fe resonance leaves a $2 \mathrm{p}$ core hole behind and an electron excited in the spin-up Fe $e$ orbital. The additional 3d electron effectively screens the core hole meaning that non-local inter-site electron transfers between the $\mathrm{Cr}$ and Fe states are little required for efficient screening. This is a notable difference with $1 \mathrm{~s}-4 \mathrm{p}$ RIXS where the core hole is weakly screened and a non-local inter-site electron transition may occur during the ultrashort lifetime of the 1s core hole. In the case of the K-edge RIXS of $\mathrm{Cu}$ in $\mathrm{La}_{2} \mathrm{CuO}_{4},{ }^{20}$ for instance, the $\mathrm{Cu} 3 \mathrm{~d}$ orbitals at the 1 s hole site are filled leaving a two-hole $\mathrm{Cu} 3 \mathrm{~d}$ state on a neighboring site. Incidentally the transfer involves SE since it occurs via the oxygen ligand.

To understand the origin of the $1.6 \mathrm{eV}$ loss in the Fe 2p RIXS process we need to consider the configuration interaction in the intermediate state. It consists of strong hybridization between $2 \mathrm{p}^{5} 3 \mathrm{~d}^{7}$ and $2 \mathrm{p}^{5} 3 \mathrm{~d}^{8} \mathrm{~L}^{-1}$ forming bonding, non-bonding, and antibonding states $\left(\mathrm{L}^{-1}\right.$ represents the transfer of an electron from the ligand). In Figure 6 the top panel shows a schematic representation of the exchange interaction in the ground state leading to the antiferromagnetic coupling between Fe and Cr. Next, the middle panel shows how the decay of the purely bonding Fe $2 \mathrm{p}^{5} 3 \mathrm{~d}^{7}$ or $\mathrm{Cr} 2 \mathrm{p}^{5} 3 \mathrm{~d}^{4}$ intermediate states can reveal the elementary low energy excitations of $0.33 \mathrm{eV}$ and $1.6 \mathrm{eV}$ for $\mathrm{Fe}$ and $\mathrm{Cr}$ respectively. The non-bonding states (not represented in Figure 6 ) give rise to the extended CT feature centered at $\approx 4.5 \mathrm{eV}$ in the RIXS spectra for both Fe and Cr. The antibonding component shown schematically 
in the two-site orbital picture of Figure 6 demonstrates that only a spin-up electron may be transferred from S 3p to the Fe site thus opening the spin-up channel to the neighboring $\mathrm{Cr}$ site. Consequently SE makes it possible to produce a $1.6 \mathrm{eV}$ loss in the Fe spectrum induced by the $\operatorname{Cr}\left(t_{2 g}^{3} e_{g}^{0}\right)$ to $\operatorname{Cr}\left(t_{2 g}^{2} e_{g}^{1}\right)$ excitation. It should be noted that in the final state no CT has taken place between Fe and the S 3p. The equivalent Cr RIXS process does not give rise to a $0.33 \mathrm{eV}$ loss because the $\operatorname{Cr} 2 \mathrm{p}^{5} 3 \mathrm{~d}^{5} \mathrm{~L}^{-1}$ state involves the transfer of a spin-down electron in accordance with Hund's rule. On the Fe site, all down-electron states are already filled so the opening of a spin-down channel has no effect.

Further light can be shed on the ligand-metal interaction by observing the CT part of the spectra at $\approx 4.5 \mathrm{eV}$ energy loss (see Figures 2,4 , and 7 ). For the Fe environment, the CT peak shifts by $2 \mathrm{eV}$ for a $2 \mathrm{eV}$ increase in $\hbar \omega_{\text {in }}$. It indicates excitation to non-bonding $e$ states only very weakly mixed with the ligand band; the Fe CT peak remains at constant energy loss. In the case of $\mathrm{Cr}$ the $\mathrm{CT}$ peak shifts by $\approx 1.0 \mathrm{eV}$ for a $2 \mathrm{eV}$ increase in incident photon energy; when plotted on an energy loss scale it disperses. The origin of such a dispersion has been discussed by Matsubara et al. ${ }^{61}$ and is dependent on a variation in CT energy over the

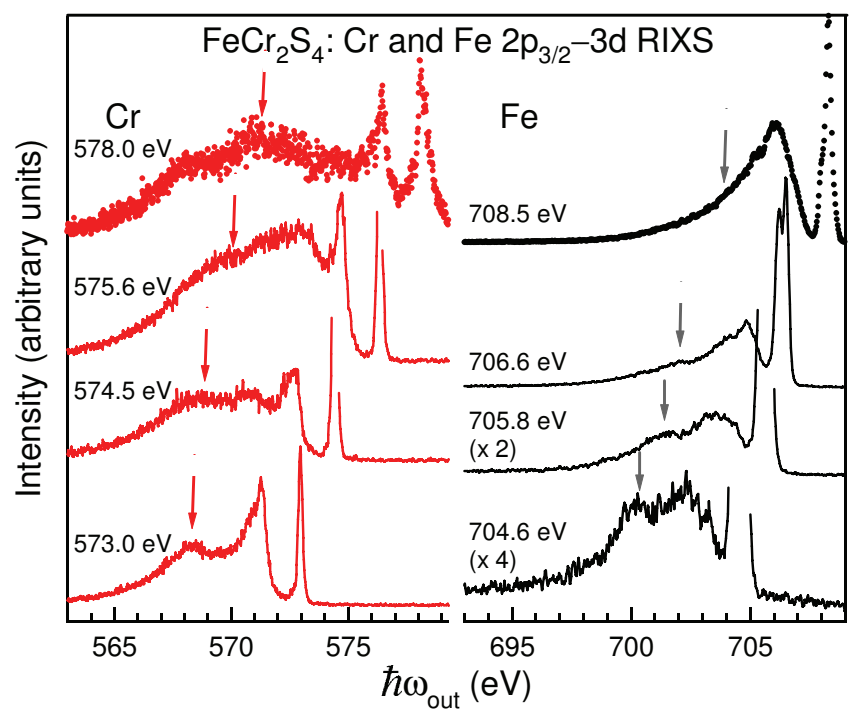

Figure 7: Charge transfer structure highlighted in $\mathrm{Cr}$ and $\mathrm{Fe} 2 \mathrm{p}_{3 / 2}-3 \mathrm{~d}$ RIXS. Some elastic peaks have been truncated for clarity. In the Cr spectra, the main CT feature does not follow the Raman shift exactly as $\hbar \omega_{\text {in }}$ increases. In the Fe spectra, the CT feature disperses as $\hbar \omega_{\text {in }}$ increases (arrows). 
width of ligand states. The $\mathrm{Cr} d$ orbitals are expected to overlap more effectively the very broad S 3p band so the center of gravity of the CT peak shifts with increasing $\hbar \omega_{\text {in. }}$ The difference in interaction within the octahedral $\mathrm{Cr}$ and tetrahedral $\mathrm{Fe}$ environments is also clear from the fluorescence data shown in the top panel of Figure 5. As $\hbar \omega_{\text {in }}$ increases above threshold energy the $1.6 \mathrm{eV}$ excitation in the Cr RIXS continues as a relatively strong peak i.e., independently of strong on-site screening of the $\operatorname{Cr} 2 \mathrm{p}$ hole. On the contrary as $\hbar \omega_{\text {in }}$ increases beyond the empty d states for Fe RIXS, the $2.0 \mathrm{eV}$ energy loss remains intense but the $1.6 \mathrm{eV}$ peak disappears.

\section{Conclusions}

Several aspects of the RIXS Fe and Cr excitations in $\mathrm{FeCr}_{2} \mathrm{~S}_{4}$ confirm the optical absorption data deduced from reflectivity measurements reported by Ohgushi et al. ${ }^{32,33}$ They observe the Fe low energy excitation at $\approx 0.3 \mathrm{eV}$ which, from our RIXS measurements, can be ascribed unambiguously to $\mathrm{Fe}\left(t_{g}^{3} e^{3}\right) \rightarrow \mathrm{Fe}\left(t_{g}^{4} e^{2}\right)$ on-site excitations thanks to the chemical sensitivity of the method. It is the feature that is linked to giant MOKE. Weak MOKE signals are also detected at $2.2 \mathrm{eV}$ and $4.5 \mathrm{eV}$ in correspondence with the main RIXS features. Only a very low intensity feature is observed at $1.6 \mathrm{eV}$ identified as relating specifically to a Cr excitation according to our analysis; no giant Kerr rotation is observed in this energy region. Our main finding is that excitations in the Fe $2 \mathrm{p}-3 \mathrm{~d}$ RIXS process provide a clear spectral fingerprint for $\mathrm{SE}$ interaction in $\mathrm{FeCr}_{2} \mathrm{~S}_{4}$. This should stimulate the development of novel models for the parametrization of SE in other 3d transition metal compounds, especially in molecular systems with heteronuclear metal centers.

\section{Acknowledgement}

The authors thank N. Jaouen for support during the measurements and R. Gaudemer for technical assistance. S.G.C., C.F.H., R.D., and J.-M.M. acknowledge the support of 
the Agence Nationale de la Recherche (ANR), under Grant No. ANR-05-NANO-074 (HRRXRS). M.G. and S.G.C. acknowledge the support of LabEx MiChem managed by the ANR under the reference ANR-11-IDEX-0004-02. Additional funding was provided by Syn-

chrotron SOLEIL and UPMC. H.D.Z. thanks the support from NSF-DMR through Award DMR-1350002.

\section{Supporting Information Available}

Tanabe-Sugano diagrams computed for $\mathrm{Fe}^{2+}$ in $T_{d}$ symmetry (Figure S1) and $\mathrm{Cr}^{3+}$ in $O_{h}$ symmetry (Figure S2) in the absence of 3d spin-orbit coupling.

This material is available free of charge via the Internet at http://pubs.acs.org/.

\section{References}

(1) Goodenough, J. B. Magnetism and the Chemical Bond; John Wiley \& Sons: New York, 1963.

(2) Zhou, H.-C.; Long, J. R.; Yaghi, O. M. Introduction to Metal-Organic Frameworks. Chem. Rev. 2012, 112, 673-674, and the articles in this special issue on MOFs.

(3) Launay, J.-P.; Verdaguer, M. Electrons in Molecules: from Basic Principles to Molecular Electronics; Oxford University Press: Oxford, 2014.

(4) Benelli, C.; Gatteschi, D. Introduction to Molecular Magnetism: from Transition Metals to Lanthanides; John Wiley \& Sons: Hoboken, NJ, 2015.

(5) Kurmoo, M. Magnetic Metal-Organic Frameworks. Chem. Soc. Rev. 2009, 38, 13531379.

(6) Bechlars, B.; D’Alessandro, D. M.; Jenkins, D. M.; Iavarone, A. T.; Glover, S. D.; Kubiak, C. P.; Long, J. R. High-Spin Ground States via Electron Delocalization in 
Mixed-Valence Imidazolate-Bridged Divanadium Complexes. Nat. Chem. 2010, 2, 362368.

(7) Tiana, D.; Hendon, C. H.; Walsh, A. Ligand Design for Long-Range Magnetic Order in Metal-Organic Frameworks. Chem. Commun. 2014, 50, 13990-13993.

(8) Gallo, E.; Lamberti, C.; Glatzel, P. dd Excitations in CPO-27-Ni Metal-Organic Framework: Comparison between Resonant Inelastic X-ray Scattering and UV-Vis Spectroscopy. Inorg. Chem. 2013, 52, 5633-5635.

(9) Lundberg, M.; Kroll, T.; DeBeer, S.; Bergmann, U.; Wilson, S. A.; Glatzel, P.; Nordlund, D.; Hedman, B.; Hodgson, K. O.; Solomon, E. I. Metal-Ligand Covalency of Iron Complexes from High-Resolution Resonant Inelastic X-ray Scattering. J. Am. Chem. Soc. 2013, 135, 17121-17134.

(10) Thomas, R.; Kas, J.; Glatzel, P.; Samarai, M. A.; de Groot, F. M. F.; Mori, R. A.; Kavčič, M.; Zitnik, M.; Bucar, K.; Rehr, J. J. et al. Resonant Inelastic X-ray Scattering of Molybdenum Oxides and Sulfides. J. Phys. Chem. C 2015, 119, 2419-2426.

(11) Kanamori, J. Superexchange Interaction and Symmetry Properties of Electron Orbitals. J. Phys. Chem. Solids 1959, 10, 87-98.

(12) Anderson, P. W. New Approach to the Theory of Superexchange Interactions. Phys. Rev. 1959, 115, 2-13.

(13) Lee, J. S.; Kim, M. W.; Noh, T. W. Optical Excitations of Transition-Metal Oxides under the Orbital Multiplicity Effects. New J. Phys. 2005, 7, 147.

(14) Oleś, A. M.; Khaliullin, G.; Horsch, P.; Feiner, L. F. Fingerprints of Spin-Orbital Physics in Cubic Mott Insulators: Magnetic Exchange Interactions and Optical Spectral Weights. Phys. Rev. B 2005, 72, 214431. 
(15) Huotari, S.; Pylkkänen, T.; Vankó, G.; Verbeni, R.; Glatzel, P.; Monaco, G. CrystalField Excitations in NiO Studied with Hard X-ray Resonant Inelastic X-ray Scattering at the Ni K edge. Phys. Rev. B 2008, 78, 041102.

(16) Ghiringhelli, G.; Matsubara, M.; Dallera, C.; Fracassi, F.; Gusmeroli, R.; Piazzalunga, A.; Tagliaferri, A.; Brookes, N. B.; Kotani, A.; Braicovich, L. NiO as a Test Case for High Resolution Resonant Inelastic Soft X-ray Scattering. J. Phys.: Condens. Matter 2005, 17, 5397-5412.

(17) Chiuzbăian, S. G.; Ghiringhelli, G.; Dallera, C.; Grioni, M.; Amann, P.; Wang, X.; Braicovich, L.; Patthey, L. Localized Electronic Excitations in NiO Studied with Resonant Inelastic X-Ray Scattering at the Ni M Threshold: Evidence of Spin Flip. Phys. Rev. Lett. 2005, 95, 197402.

(18) Wray, L. A.; Yang, W.; Eisaki, H.; Hussain, Z.; Chuang, Y.-D. Multiplet Resonance Lifetimes in Resonant Inelastic X-ray Scattering Involving Shallow Core Levels. Phys. Rev. B 2012, 86, 195130.

(19) Duda, L.-C.; Schmitt, T.; Magnuson, M.; Forsberg, J.; Olsson, A.; Nordgren, J.; Okada, K.; Kotani, A. Resonant Inelastic X-Ray Scattering at the Oxygen K Resonance of NiO: Nonlocal Charge Transfer and Double-Singlet Excitations. Phys. Rev. Lett. 2006, 96, 067402.

(20) Forte, F.; Ament, L. J. P.; van den Brink, J. Single and Double Orbital Excitations Probed by Resonant Inelastic X-Ray Scattering. Phys. Rev. Lett. 2008, 101, 106406.

(21) Ulrich, C.; Ament, L. J. P.; Ghiringhelli, G.; Braicovich, L.; Moretti Sala, M.; Pezzotta, N.; Schmitt, T.; Khaliullin, G.; van den Brink, J.; Roth, H. et al. Momentum Dependence of Orbital Excitations in Mott-Insulating Titanates. Phys. Rev. Lett. 2009, 103, 107205. 
(22) Wohlfeld, K.; Daghofer, M.; Nishimoto, S.; Khaliullin, G.; van den Brink, J. Intrinsic Coupling of Orbital Excitations to Spin Fluctuations in Mott Insulators. Phys. Rev. Lett. 2011, 107, 147201.

(23) Schlappa, J.; Wohlfeld, K.; Zhou, K. J.; Mourigal, M.; Haverkort, M. W.; Strocov, V. N.; Hozoi, L.; Monney, C.; Nishimoto, S.; Singh, S. et al. Spin-Orbital Separation in the Quasi-One-Dimensional Mott Insulator $\mathrm{Sr}_{2} \mathrm{CuO}_{3}$. Nature 2012, 485, 82-85.

(24) Néel, L. Propriétés Magnétiques des Ferrites: Ferrimagnétisme et Antiferromagnétisme. Ann. Phys. (Paris) 1948, 3, 137-198.

(25) Lotgering, F. K. On the Ferrimagnetism of Some Sulphides and Oxides. Philips Res. Rep. 1956, 11, 190-249.

(26) Bongers, P. F.; Haas, C.; van Run, A. M. J. G.; Zanmarchi, G. Magnetoresistance in Chalcogenide Spinels. J. Appl. Phys. 1969, 40, 958-963.

(27) Goodenough, J. B. Descriptions of Outer d Electrons in Thiospinels. J. Phys. Chem. Solids 1969, 30, 261-280.

(28) Ramirez, A. P.; Cava, R. J.; Krajewski, J. Colossal Magnetoresistance in Cr-Based Chalcogenide Spinels. Nature 1997, 386, 156-159.

(29) Coey, J. M. D.; Viret, M.; von Molnár, S. Mixed-Valence Manganites. Adv. Phys. 1999, 48, 167-293.

(30) Bertinshaw, J.; Ulrich, C.; Gunther, A.; Schrettle, F.; Wohlauer, M.; Krohns, S.; Reehuis, M.; Studer, A. J.; Avdeev, M.; Quach, D. V. et al. $\mathrm{FeCr}_{2} \mathrm{~S}_{4}$ in Magnetic Fields: Possible Evidence for a Multiferroic Ground State. Sci. Rep. 2014, 4, 6079.

(31) Lin, L.; Zhu, H. X.; Jiang, X. M.; Wang, K. F.; Dong, S.; Yan, Z. B.; Yang, Z. R.; Wan, J. G.; Liu, J. M. Coupled Ferroelectric Polarization and Magnetization in Spinel $\mathrm{FeCr}_{2} \mathrm{~S}_{4}$. Sci. Rep. 2014, 4, 6530. 
(32) Ohgushi, K.; Ogasawara, T.; Okimoto, Y.; Miyasaka, S.; Tokura, Y. Gigantic Kerr Rotation Induced by a d-d Transition Resonance in $\mathrm{MCr}_{2} \mathrm{~S}_{4}(\mathrm{M}=\mathrm{Mn}, \mathrm{Fe})$. Phys. Rev. $B$ 2005, 72, 155114.

(33) Ohgushi, K.; Okimoto, Y.; Ogasawara, T.; Miyasaka, S.; Tokura, Y. Magnetic, Optical, and Magnetooptical Properties of Spinel-Type $\mathrm{ACr}_{2} \mathrm{X}_{4}(\mathrm{~A}=\mathrm{Mn}, \mathrm{Fe}, \mathrm{Co}, \mathrm{Cu}, \mathrm{Zn}, \mathrm{Cd}$; $\mathrm{X}=\mathrm{O}, \mathrm{S}, \mathrm{Se})$. J. Phys. Soc. Jpn. 2008, 77, 034713.

(34) Berry, F. J.; Dmitrieva, T. V.; Ovanesyan, N. S.; Lyubutin, I. S.; Thomas, M. F.; Sarkisyan, V. A.; Ren, X.; Aminov, T. G.; Shabunina, G. G.; Rudenko, V. et al. Magnetic Order in $\mathrm{FeCr}_{2} \mathrm{~S}_{4}$-Type Chalcogenide Spinels. J. Phys.: Condens. Matter 2007, 19, 266204.

(35) Amiel, Y.; Rozenberg, G. K.; Nissim, N.; Milner, A.; Pasternak, M. P.; Hanfland, M.; Taylor, R. D. Intricate Relationship between Pressure-Induced Electronic and Structural Transformations in $\mathrm{FeCr}_{2} \mathrm{~S}_{4}$. Phys. Rev. B 2011, 84, 224114.

(36) Ament, L. J. P.; van Veenendaal, M.; Devereaux, T. P.; Hill, J. P.; van den Brink, J. Resonant Inelastic X-ray Scattering Studies of Elementary Excitations. Rev. Mod. Phys. 2011, 83, 705-767.

(37) Sugano, S.; Tanabe, Y.; Kamimura, H. Multiplets of Transition-Metal Ions in Crystals; Series: Pure and Applied Physics; Academic Press: New York, 1970; Vol. 33.

(38) Chiuzbăian, S. G.; Hague, C. F.; Avila, A.; Delaunay, R.; Jaouen, N.; Sacchi, M.; Polack, F.; Thomasset, M.; Lagarde, B.; Nicolaou, A. et al. Design and Performance of AERHA, a High Acceptance High Resolution Soft X-ray Spectrometer. Rev. Sci. Instrum. 2014, 85, 043108.

(39) Sacchi, M.; Jaouen, N.; Popescu, H.; Gaudemer, R.; Tonnerre, J.-M.; Chiuzbăian, S. G.; Hague, C. F.; Delmotte, A.; Dubuisson, J. M.; Cauchon, G. et al. The SEXTANTS 
Beamline at SOLEIL: a New Facility for Elastic, Inelastic and Coherent Scattering of Soft X-rays. J. Phys. Conf. Ser. 2013, 425, 072018.

(40) Watanabe, T. Growth of $\mathrm{CoCr}_{2} \mathrm{~S}_{4}$ and $\mathrm{FeCr}_{2} \mathrm{~S}_{4}$ Single Crystals by Chemical Vapor Transport. J. Phys. Soc. Jpn. 1972, 32, 1443-1443.

(41) Stavitski, E.; de Groot, F. M. F. The CTM4XAS Program for EELS and XAS Spectral Shape Analysis of Transition Metal L Edges. Micron 2010, 41, 687-694.

(42) Cowan, R. D. The Theory of Atomic Spectra and Structure; Los Alamos Series in Basic and Applied Sciences; University of California Press: Berkeley, CA, 1981; Vol. 3.

(43) (a) Kramers, H. A.; Heisenberg, W. Über die Streuung von Strahlung durch Atome. Z. Phys. 1925, 31, 681-708; (b) Heitler, W. The Quantum Theory of Radiation, 3rd ed.; Clarendon Press: Oxford, 1954.

(44) Keski-Rahkonen, O; Krause, M. O. Total and Partial Atomic-level Widths. At. Data and Nucl. Data Tables 1974, 14, 139-146.

(45) Fuggle, J. C., Inglesfield, J. E., Eds. Unoccupied Electronic States; Topics in Applied Physics; Springer Verlag: Berlin, Heidelberg, New York, 1992; Vol. 69; Chapter "Corehole lifetime broadenings" (Appendix B), pp 347-351.

(46) Kang, J.-S.; Kim, G.; Lee, H. J.; Kim, H. S.; Kim, D. H.; Han, S. W.; Kim, S. J.; Kim, C. S.; Lee, H.; Kim, J.-Y. et al. Synchrotron Radiation Spectroscopy Study of $\mathrm{FeCr}_{2} \mathrm{X}_{4}(\mathrm{X}=\mathrm{S}$ and Se). J. Appl. Phys. 2008, 103, 07D717.

(47) Verma, V. K.; Singh, V. R.; Ishigami, K.; Shibata, G.; Harano, T.; Kadono, T.; Fujimori, A.; Koide, T.; Tokura, Y. X-ray Magnetic Circular Dichroism Study of $\mathrm{FeCr}_{2} \mathrm{~S}_{4}$. Photon Factory Activity Report 2011 2012, 29 Part B, 129.

(48) Kang, J.-S.; Hwang, J.; Kim, D. H.; Lee, E.; Kim, W. C.; Kim, C. S.; Lee, H.-K.; Kim, J.-Y.; Han, S. W.; Hong, S. C. et al. Soft X-ray Magnetic Circular Dichroism 
Study of Valence and Spin States in $\mathrm{FeT}_{2} \mathrm{O}_{4}(\mathrm{~T}=\mathrm{V}, \mathrm{Cr})$ Spinel Oxides. J. Appl. Phys. 2013, 113, 17E116.

(49) Regan, T. J.; Ohldag, H.; Stamm, C.; Nolting, F.; Lüning, J.; Stöhr, J.; White, R. L. Chemical Effects at Metal/Oxide Interfaces Studied by X-ray-Absorption Spectroscopy. Phys. Rev. B 2001, 64, 214422.

(50) Tsurkan, V.; Demeter, M.; Schneider, B.; Hartmann, D.; Neumann, M. Exchange Splitting of the Cr, Fe and Mn 3s XPS Spectra in Some Ternary Magnetic Semiconductor Sulphides. Solid State Commun. 2000, 114, 149-154.

(51) van der Laan, G.; Kirkman, I. W. The 2p Absorption Spectra of 3d Transition Metal Compounds in Tetrahedral and Octahedral Symmetry. J. Phys.: Condens. Matter 1992, 4, 4189-4204.

(52) Sarkar, S.; De Raychaudhury, M.; Dasgupta, I.; Saha-Dasgupta, T. Electronic Structure of $\mathrm{FeCr}_{2} \mathrm{~S}_{4}$ : Evidence of Coulomb Enhanced Spin-Orbit Splitting. Phys. Rev. B 2009, $80,201101(\mathrm{R})$.

(53) Sarkar, S.; Maitra, T.; Valentí, R.; Saha-Dasgupta, T. Comparative Study of FeCr $_{2} \mathrm{~S}_{4}$ and $\mathrm{FeSc}_{2} \mathrm{~S}_{4}$ : Spinels with Orbitally Active A Site. Phys. Rev. B 2010, 82, 041105.

(54) Theil, C.; van Elp, J.; Folkmann, F. Ligand Field Parameters Obtained from and Chemical Shifts Observed at the $\mathrm{Cr} \mathrm{L}_{2,3}$ Edges. Phys. Rev. B 1998, 59, 7931-7936.

(55) de Groot, F.; Kotani, A. Core Level Spectroscopy of Solids; Advances in Condensed Matter Science; CRC Press: Boca Raton, FL, 2008; Chapter 4.

(56) Lo Presti, L.; Destro, R. Experimental and Theoretical Charge Density Distribution of the Colossal Magnetoresistive Transition Metal Sulfide $\mathrm{FeCr}_{2} \mathrm{~S}_{4}$. J. Chem. Phys. 2008, 128, 044710. 
(57) Gel'mukhanov, F.; Ågren, H. Resonant X-ray Raman Scattering. Phys. Rep. 1999, 312, $87-330$.

(58) Slack, G. A.; Ham, F. S.; Chrenko, R. M. Optical Absorption of Tetrahedral Fe ${ }^{2+}\left(3 \mathrm{~d}^{6}\right)$ in Cubic ZnS, CdTe, and $\mathrm{MgAl}_{2} \mathrm{O}_{4}$. Phys. Rev. 1966, 152, 376-402.

(59) Kurmaev, E. Z.; Postnikov, A. V.; Palmer, H. M.; Greaves, C.; Bartkowski, S.; Tsurkan, V.; Demeter, M.; D. Hartmann, D.; Neumann, M.; Zatsepin, D. A. et al. Electronic Structure of $\mathrm{FeCr}_{2} \mathrm{~S}_{4}$ and $\mathrm{Fe}_{0.5} \mathrm{Cu}_{0.5} \mathrm{Cr}_{2} \mathrm{~S}_{4}$. J. Phys.: Condens. Matter 2000, 12, 5411-5421.

(60) Figgis, B. N. Introduction to Ligand Fields; John Wiley \& Sons: New York, 1966.

(61) Matsubara, M.; Uozumi, T.; Kotani, A.; Parlebas, J.-C. Charge Transfer Excitation in Resonant X-ray Emission Spectroscopy of NiO. J. Phys. Soc. Jpn 2005, 74, 2052-2060. 


\section{Graphical TOC Entry}

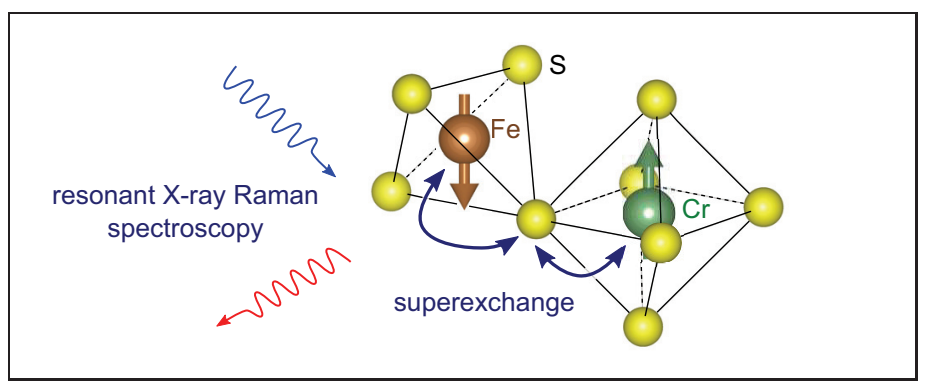

